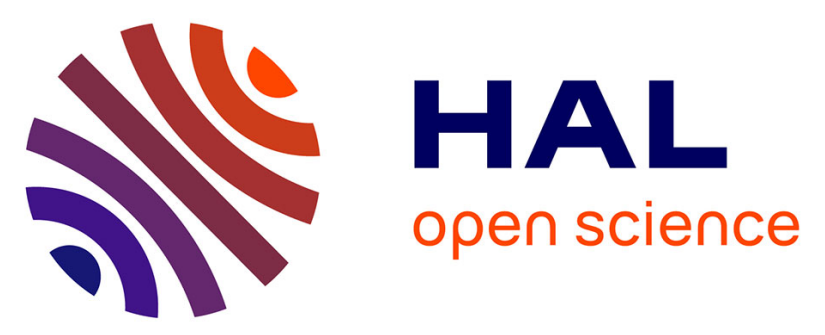

\title{
Innovative depollution treatment using multi-valent iron species: from fundamental study to application in municipal wastewater
}

Olivier Monfort, Guillaume Voyard, Marcello Brigante, Gilles Mailhot

\section{- To cite this version:}

Olivier Monfort, Guillaume Voyard, Marcello Brigante, Gilles Mailhot. Innovative depollution treatment using multi-valent iron species: from fundamental study to application in municipal wastewater. Environmental Science and Pollution Research, 2020, 27 (16), pp.19736-19745. 10.1007/s11356-02008502-z . hal-02932226

\section{HAL Id: hal-02932226 \\ https://hal.science/hal-02932226}

Submitted on 7 Sep 2020

HAL is a multi-disciplinary open access archive for the deposit and dissemination of scientific research documents, whether they are published or not. The documents may come from teaching and research institutions in France or abroad, or from public or private research centers.
L'archive ouverte pluridisciplinaire HAL, est destinée au dépôt et à la diffusion de documents scientifiques de niveau recherche, publiés ou non, émanant des établissements d'enseignement et de recherche français ou étrangers, des laboratoires publics ou privés. 


\title{
Innovative depollution treatment using multi-valent iron species: From fundamental study to application
} in municipal wastewater

\author{
Olivier Monfort ${ }^{1, *}$, Guillaume Voyard, Marcello Brigante, Gilles Mailhot
}

Université Clermont Auvergne, CNRS, SIGMA Clermont, Institut de Chimie de Clermont-Ferrand, F-63000

Clermont-Ferrand, France

${ }^{1}$ permanent address : Comenius University in Bratislava, Faculty of Natural Sciences, Department of Inoganic Chemistry, Ilkovicova 6, Mlynska Dolina, 84215 Bratislava, Slovakia

*corresponding author : monfort1@uniba.sk

\begin{abstract}
In this work, a new combination of oxidation treatments for the degradation of bisphenol A (BPA) is investigated. This innovative wastewater (WW) treatment includes the use of ferrate $\left(\mathrm{FeO}_{4}{ }^{2-}\right)$ and its decomposition byproducts under dark and UVA irradiation. The oxidation by ferrate leads to a fast but incomplete degradation of BPA with a degradation extent of $45 \%$ after 60 minutes under adopted experimental conditions. However, the ferrate decomposition byproducts which are constituted by solid iron species can be used to further improve the pollutant degradation efficiency. Indeed, ferrate-mediated heterogeneous photoFenton process is employed for the first time to enhance the degradation of BPA. With respect to the application for wastewater treatment, UVA irradiation (which is part of solar light), non-toxic and natural origin compounds such as ascorbic acid (AA) and ethylenediamine-N,N'-disuccinic acid (EDDS) are used to design a sustainable process. Under optimized conditions, the degradation extent of BPA using this newly designed treatment reaches almost $100 \%$ with AA and $70 \%$ with EDDS. In order to assess the feasibility of this treatment, the ferratemediated photo-Fenton process is applied to treat municipal wastewater. The obtained results in WW are highly encouraging since a maximum BPA degradation extent of $63 \%$ and $60 \%$ is observed after 300 min by using AA and EDDS, respectively.
\end{abstract}

\section{Keywords}


Advanced oxidation process; Wastewater treatment; Environmental chemistry; Photo-Fenton; Ferrate; Hydroxyl radical

\section{Introduction}

For several decades, different chemical oxidation processes are investigated in order to degrade the organic recalcitrant pollutant in water. Ferrate $\left(\mathrm{FeO}_{4}{ }^{2-}\right)$ is considered as a promising oxidant for the removal of contaminants in the environment (Dong et al. 2019; Jiang et al. 2018; Luo et al. 2019; Monfort et al. 2019; Peings et al. 2017; Sharma et al. 2015, 2016; Xie and Cheng 2019). Although the chemistry of ferrate is sophisticated and not yet fully understood (Han et al. 2018; Lee et al. 2014; Machalova Siskova et al. 2016; Sharma 2010; Sharma et al. 2011, 2015, Yu et al. 2017), ones of its undoubtedly advantages is its oxidation properties (2.2 V vs. SHE in acidic medium) (Jiang and Lloyd 2002) and its high reactivity (Chen et al. 2018; Rush and Bielski 1994; Sharma 2002, 2013). Compared to "classic" oxidants such as permanganate $\left(\mathrm{MnO}_{4}{ }^{-}\right)$, hydrogen peroxide $\left(\mathrm{H}_{2} \mathrm{O}_{2}\right)$ and ozone $\left(\mathrm{O}_{3}\right)$, ferrate can degrade more efficiently a wider range of organic pollutants such as pesticides, pharmaceuticals or emerging pollutants (Feng and Baum 2019; Han et al. 2015; Peings et al. 2017; Sharma et al. 2016). However, the mineralization of target contaminants in water using reasonable ferrate concentrations is never completely achieved. For this reason, several strategies have been proposed to improve the oxidation by ferrate. One of them is the use of sulfate-based radical precursors to produce reactive sulfate species which increase the mineralization extent (Feng et al. 2019, 2018; Feng and Sharma 2018; Shao et al. 2019; Sun et al. 2018; Zhang et al. 2017). Thus, the combination of sulfite and ferrate leads to the formation sulfate and/or hydroxyl radicals $\left(\mathrm{SO}_{4}{ }^{-}, \mathrm{HO}^{\circ}\right)$ which enhance the degradation efficiency of the target molecule (Feng and Sharma 2018; Shao et al. 2019; Sun et al. 2018). Another strategy is the use of the coagulation properties of ferrate since their decomposition byproducts are Fe(III) species (Jiang 2007; Zheng and Deng 2016) or the use of ferrate as pre-oxidation step in conventional chemical treatments $\left(\mathrm{TiO}_{2}\right.$ photocatalysis or $\mathrm{H}_{2} \mathrm{O}_{2}$ photolysis) (Ma et al. 2015; Matin et al. 2018; Sharma et al. 2001, 2010; Wang et al. 2010). However, these processes imply the addition of hazardous chemicals or the displacement of the pollution (in the case of coagulation) which is not economically and environmentally viable.

It is admitted that ferrate decomposes into Fe(III) oxides/hydroxides. Recently, Goodwill et al. have demonstrated that the reduction of ferrate reduction yields to crystallized ferric species such as $\mathrm{Fe}_{2} \mathrm{O}_{3}(\mathrm{Goodwill}$ et al. 2015; Jiang et al. 2015; Lv et al. 2018). Therefore, heterogeneous Fenton and photo-Fenton processes can be potentially applied to improve the oxidation process of ferrate, and this is for the first time demonstrated here 
in the so-called ferrate-mediated photo-Fenton oxidation process. Although heterogeneous photo-Fenton processes have several drawbacks compared to homogeneous systems (availability of iron, lower efficiency, etc.), their strongest advantage is the efficiency at environmentally relevant $\mathrm{pH}$ (from 5.5 to 8.0 ), which is an important condition for the engineering of water and wastewater treatments (Miklos et al. 2018; Wang et al. 2016).

In this work, the improvement of oxidation by ferrate is operated through the valorization of its decomposition byproducts using advanced oxidation processes (AOPs) including photo-Fenton process. In the literature, few works are focused on comparative studies between these two types of oxidation treatments (Batarseh et al. 2007; Vela-Gala et al. 2014; Zboril et al. 2012) but none of them has ever tested the combination of ferrate and Fenton-based oxidation processes in a single treatment. In addition, UVA irradiation and natural/non-toxic compounds are used in this work to valorize the ferrate decomposition byproducts (Hou et al. 2016; Huang W et al. 2013, 2017; Wang et al. 2019) and to design a sustainable treatment. Published works devoted to the application of ferrate-based processes in real wastewater are scarce (Jiang et al. 2018); therefore, to assess the feasibility of such an innovative treatment, it is tested in the depollution of water from municipal wastewater plant. Bisphenol A (BPA) is chosen as model pollutant since it is a persistent endocrine disruptor widely spread in the environment (Crain et al. 2007; Suzuki et al. 2004) and thus, a good probe to investigate the efficiency of this ferrate-mediated heterogeneous photo-Fenton processes. BPA is a contaminant from plastic products (including packaging materials) which easily leaches out into the environment and food (Nomiri et al. 2019). BPA exposure is associated to many human diseases including diabetes, cancer, hepatotoxicity or hormonal deregulation (Nomiri et al. 2019).

\section{Materials and methods}

\subsection{Chemicals}

Potassium ferrate $\left(\mathrm{K}_{2} \mathrm{FeO}_{4}\right)$, pure $(98 \%)$ and in the form of mixture (20\%), were purchased from Santa Cruz Biotechnology and NanoIron (Czech Republic), respectively. Hydrogen peroxide $\left(\mathrm{H}_{2} \mathrm{O}_{2}, 30 \%\right.$ in water), Lascorbic acid (AA, reagent grade), Ethylenediamine-N,N'-disuccinic acid trisodium salt solution (EDDS, 35\% in water), bisphenol A (BPA, 99\%), 3-(2pyridyl)-5,6-diphenyl-1,2,4-triazine-4',4'’disulfonic acid sodium salt (ferrozine, 97\%), 4-hydroxyphenylacetic acid (HPAA, 98\%), Ethylenediaminetetraacetic disodium salt (EDTA, 99\%), peroxidase from horseradish (POD) and 2,2'-azino-bis(3-ethylbenzothiazoline-6-sulfonate) (ABTS) were supplied by Sigma-Aldrich. The chemicals were used without further purification and the solutions were 
prepared with ultra-pure water (milli-Q system from Millipore; $18.2 \mathrm{M} \Omega \mathrm{cm}$ ) except when it is specified. The $\mathrm{pH}$ of the solution was adjusted with perchloric acid $\left(\mathrm{HClO}_{4}\right)$ when necessary. Ferric oxide/hydroxide powder including hematite $\left(\mathrm{Fe}_{2} \mathrm{O}_{3}\right)$ and goethite $(\mathrm{FeOOH})$ were obtained also from Sigma-Aldrich.

\subsection{Characterization methods}

The potassium ferrate salt in the form of mixture was characterized by SEM/EDX in order to investigate the chemical composition. Results were compared to those from pure ferrate. These semi-quantitative chemical analyses were performed by SEM using a Cameca SX100 device equipped with EDX (SDD brüker). In addition, the concentration of ferrate in solutions from the pure and mixture forms is investigated by a colorimetric method using ABTS (see Text 1 in ESM). The decomposition byproducts of the ferrate mixture were analyzed by XRD using PANalytical X'Pert Pro X-ray diffractometer (Bragg Brentano geometry; $\mathrm{Cu}-\mathrm{K} \alpha$ radiation) equipped with an X-Celerator Scientific detector to determine the crystalline phase composition. In solution, the stability of the ferrate mixture at different concentrations was investigated both in the dark and under UVA irradiation using UV-visible spectroscopy (Varian Cary $3 \mathrm{UV}$-visible spectrophotometer) with a $5 \mathrm{~cm}$ and $1 \mathrm{~cm}$ path length quartz cells for $0.04 \mathrm{~g} \mathrm{~L}^{-1}$ and $0.4 \mathrm{~g} \mathrm{~L}^{-1}$ ferrate solution, respectively.

\subsection{Degradation experiments and analysis of BPA}

All experiments in the dark and under UVA irradiation were performed in batch mode. Typically, the degradation of $50 \mu \mathrm{M}$ of BPA was investigated using different concentrations of ferrate ranging from 0.01 to 0.4 $\mathrm{g} \mathrm{L}^{-1}$ in the dark and under UVA. Other experimental conditions were also tested to improve the degradation efficiency. To this end, after $1 \mathrm{~h}$ of oxidation by ferrate in the dark, different concentrations of AA or EDDS were added to the solution. Then, after 30 min kept, $\mathrm{H}_{2} \mathrm{O}_{2}$ was spiked into the solution to trigger the (photo)Fenton reaction either in the dark or under irradiation. For irradiation experiments, the solution was placed in a thermostated (293 \pm 2 K) Pyrex reactor in which 4 UVA lamps (Sylvania Black light F15W/350BL-T8) were located on the top. The emission spectrum reaching the solution was quantified to be $1.89 \mathrm{~mW} \mathrm{~cm}^{-2}$ between 290 and $400 \mathrm{~nm}$ with a maximum at $350 \mathrm{~nm}$ (Fig S1).

To assess the degradation extent, $500 \mu \mathrm{L}$ samples were withdrawn at fixed time intervals, filtered using $0.45 \mu \mathrm{m}$ PTFE filter and quenched into $500 \mu \mathrm{L}$ of methanol (MeOH) to stop the reaction. The BPA concentration in the sample was determined using High Performance Liquid Chromatography (HPLC, Nexera LC-20AD XR) equipped with C18 column (Agilent) and diode array detector (prominence SPD-M20A) set at $225 \mathrm{~nm}$. The 
mobile phase was composed of a mixture of milli-Q water and $\mathrm{MeOH}$ in gradient mode $\left(\mathrm{H}_{2} \mathrm{O} / \mathrm{MeOH}\right.$ from 55:45 to $30: 70$ reached in $8 \mathrm{~min}$ ). The flow rate was $1.0 \mathrm{~mL} \mathrm{~min}^{-1}$ and injection volume was $25 \mu \mathrm{L}$.

\subsection{Assessment of $\mathrm{Fe}(\mathrm{II})$ and $\mathrm{H}_{2} \mathrm{O}_{2}$ concentrations in solution}

$\mathrm{Fe}$ (II) formation in solution was determined using a ferrozine complexation method (Stookey 1970). Briefly, 500 $\mu \mathrm{L}$ of sample was mixed with $50 \mu \mathrm{L}$ of $20 \mathrm{mM}$ ferrozine solution in $100 \mu \mathrm{L}$ of phosphate buffer solution $(\mathrm{pH}=$ 6.5). Then, using the Beer-Lambert law with the maximum absorbance of Fe(II)-ferrozine complex at $562 \mathrm{~nm}$ and an extinction coefficient $\left(\varepsilon=27900 \mathrm{M}^{-1} \mathrm{~cm}^{-1}\right)$, the concentration of Fe(II) can be determined.

$\mathrm{H}_{2} \mathrm{O}_{2}$ concentration in solution was determined using fluorescence detection. Briefly, $500 \mu \mathrm{L}$ of the sample was added to a mixture of $2 \mathrm{~mL}$ of $1 \mathrm{mM}$ HPAA and $1 \mathrm{~mL}$ of a phosphate buffer solution (pH 6.5) containing $10 \mathrm{mM}$ EDTA and few mg of POD. In presence of $\mathrm{H}_{2} \mathrm{O}_{2}$, the POD catalyzed the formation of highly fluorescent HPAA dimer which was detected using fluorescence spectrophotometer (Varian Cary Eclipse) at $410 \mathrm{~nm}$ for an excitation wavelength of $320 \mathrm{~nm}$.

\subsection{Application to municipal wastewater}

Wastewater (WW), after a primary treatment stage, was collected the $24^{\text {th }}$ September 2019 in a municipal wastewater treatment plant of the metropole of Clermont-Ferrand. In order to remove the solid particles, filtration using $0.45 \mu \mathrm{m}$ PTFE filter was performed. Analyses using total organic carbon (Shimadzu, TOC-L) and ionic chromatography (Thermo Scientific, ICS5000) exhibited that, among the $60 \mathrm{mgC} \mathrm{L}^{-1}$ contained in the $\mathrm{WW}$, around $35 \mathrm{mgC} \mathrm{L}^{-1}$ is from organic compounds while ions concentrations are reported in Table $\mathrm{S} 1$. The $\mathrm{pH}$ of WW was 8.0. The same experimental conditions as those described in section 2.3 were used to investigate the feasibility of the ferrate-mediated heterogeneous photo-Fenton process in the treatment of municipal wastewater.

\section{Results and discussion}

\subsection{Characterization of ferrate and its decomposition byproducts}

\subsubsection{SEM/EDX and XRD}

Since the solid ferrate mixture dissolves in water, the main purpose of SEM/EDX analysis is to investigate the chemical element composition and repartition within the solid salt (Fig. 1). The ferrate mixture is essentially composed of $\mathrm{K}, \mathrm{Fe}$, and $\mathrm{O}$ chemical elements with trace amount of $\mathrm{Cl}$ (Table 1). The elements distribution is heterogeneous (Fig. 1) and according to the semi-quantitative EDX analysis recorded in the marked zones in Fig. 
1A, the solid compound contains a mixture of ferrates with different stoichiometries (i.e. different iron oxidation states). In addition, the ferrate is embedded in a matrix which is rich in potassium (especially $\mathrm{KOH}$ and to a smaller extent $\mathrm{KCl}$ ). This is probably due to byproducts from ferrate synthesis (Jiang and Lloyd 2002; Sharma et al. 2016). For comparison, the pure ferrate is also investigated by SEM/EDX (Fig. S2). Although only ferrate(VI) is identified in the pure form, the solid compound contains a large amount of impurities which is not consistent with the information from the supplier. These impurities are composed of $\mathrm{KOH}$ and $\mathrm{KCl}$ (Fig. S2). In addition, the concentration of ferrate in both the pure form and the mixture is calculated to be similar according to titration by the ABTS method (see Text S1 in ESM). Therefore, for economic and scientific reasons, ferrate mixture is used in this work to investigate the ferrate-mediated oxidation processes for WW treatment.

Concerning the byproducts from ferrate decomposition in water, XRD analysis exhibits both amorphous and crystalline phase. The crystalline phase is identified as magnetite $\left(\mathrm{Fe}_{3} \mathrm{O}_{4}\right)$ (Fig. S3). The presence of this mixed valence iron oxide in decomposed ferrate is beneficial since $\mathrm{Fe}_{3} \mathrm{O}_{4}$ is efficient in heterogeneous photoFenton process (Huang W et al. 2017). On the other hand, amorphous iron oxides/hydroxides undergo leaching which is an advantage for homogenous Fenton-type reactions (Prucek et al. 2009). Usually, ferrate is decomposed into hematite (Miklos et al. 2018), thus the presence of magnetite in the decomposition byproducts from the ferrate mixture is a new finding reported for the first time here. Regarding the low number of publications devoted to the control of iron oxide formation from ferrate decomposition, such a research field would be of high interest in the future.

\subsubsection{Stability of ferrate in solution}

The stability of ferrate solution $\left(0.04 \mathrm{~g} \mathrm{~L}^{-1}, \mathrm{pH}=10.0\right)$ is investigated in the dark and under UVA irradiation (Fig. S4A). From the UV-visible spectra, a decrease of the characteristic absorption band of ferrate centered at $505 \mathrm{~nm}$ (Licht et al. 2001; Rush et al. 1996) is observed upon ageing the solution. This decrease is accelerated under UVA irradiation suggesting a photo-induced decomposition. After adjusting the pH to acidic values $(\mathrm{pH}=5.0)$, the stability of ferrate rapidly decreases and almost the complete decomposition is observed after 2 min (Fig. S4A). This is explained by considering the short lifetime of ferrate species in acidic media in which they are much more reactive (Rush and Bielski 1996; Sharma 2002). Similarly, pure ferrate solution (0.04 $\mathrm{g} \mathrm{L}^{-1}$ ) exhibits the same tendency (Fig. S4B).

At higher concentrations, the stability of ferrate mixture solution slightly decreases (Fig. S4C). This is due to the increase of nucleation sites since ferrate decomposes into solid iron species (R1) which favor 
decomposition/precipitation of ferrate (Miklos et al. 2018; Wang et al. 2016). In addition, in the presence of BPA, complete decomposition of ferrate is obtained within several minutes probably due to the high reactivity toward electron rich moieties (Fig. S4D).

$2 \mathrm{FeO}_{4}{ }^{2-}{ }_{(\mathrm{aq})}+5 \mathrm{H}_{2} \mathrm{O} \quad \rightarrow \quad 2 \mathrm{Fe}(\mathrm{OH})_{3(\mathrm{~s})}+4 \mathrm{OH}^{-}+3 / 2 \mathrm{O}_{2}$

\subsection{Degradation of BPA}

\subsubsection{Oxidation process by ferrate and its valorization under UVA}

The degradation of BPA by oxidation in the presence of ferrate is very fast (Fig. 2). No pH adjustment is performed, and $\mathrm{pH}$ of the solution is measured at 10. The fast BPA degradation in Fig. 2 is due to its high oxidation potential and fast kinetic since the time of reaction between ferrate and most of organic pollutants containing electron rich moieties is ranging from seconds to minutes (Sharma 2002). Moreover, ferrate acts through direct oxidation, i.e. 1 or 2 electrons transfer (Han et al. 2015; Sharma et al. 2016). The effect of ferrate concentration on the degradation extent of BPA is shown in Fig. 2A. As expected, the removal extent of BPA increases with the ferrate concentration and reaches approximatively $85 \%$ after $120 \mathrm{~min}$ in the dark at $0.4 \mathrm{~g} \mathrm{~L}^{-1}$ of ferrate (Fig. 2A). However, the maximum degradation extent tends to a limit with a large excess of ferrate (Fig. 2B). Indeed, self-decomposition of ferrate (R1) becomes more important at higher concentration and it is not favorable to BPA removal (Han et al. 2015). To study the ferrate-mediated heterogeneous photo-Fenton process, the concentration of $0.04 \mathrm{~g} \mathrm{~L}^{-1}$ was chosen for the following parts of the work in order to better observe negative/positive effects of tested parameters.

UVA irradiation was also turned on during the degradation of BPA to improve the oxidation process. Indeed, the ferrate decomposition leads to the production of $\mathrm{H}_{2} \mathrm{O}_{2}$ in our experimental conditions (Fig. S5), which is in accordance to the literature (Lee et al. 2014; Sharma et al. 2015). Although UVA irradiation can trigger photochemical activation of $\mathrm{H}_{2} \mathrm{O}_{2}$ to produce hydroxyl radicals ( $\mathrm{HO}^{\circ}$ ) (Huang W et al. 2018), the effect of irradiation on the BPA degradation by ferrate oxidation exhibits a negligible increase, from 53\% to $58 \%$ after 60 min (Fig. S6). To improve BPA degradation extent, the irradiation of the solution is applied once the ferrate is fully decomposed (i.e. after $60 \mathrm{~min}$ ) for 2 main reasons: (i) solid iron oxides/hydroxides from ferrate have different physico-chemical properties compared to those of synthetic oxides/hydroxides (Batarseh et al. 2007; Miklos et al. 2018; Wang et al. 2016) and (ii) decomposed ferrate contains crystallized magnetite (section 3.1.1). This ferrate-mediated heterogeneous photo-Fenton process, in presence or absence of $\mathrm{H}_{2} \mathrm{O}_{2}$ is reported in Fig. 3, 
where different steps can be identified. The first one corresponds to the fast degradation of BPA in the presence of ferrate (from 0 to $60 \mathrm{~min}$ ). A second step starting from 60 min corresponds to the effect UVA radiation which triggers photo-Fenton process, thus BPA further degrades, especially in the presence of $1 \mathrm{mM} \mathrm{H}_{2} \mathrm{O}_{2}$. In other words, the BPA degradation is assigned to Fe(III) photolysis (R2) and reactivity of photogenerated Fe(II) with $\mathrm{H}_{2} \mathrm{O}_{2}$ (R3). However, this new combined oxidation treatment is efficient only at $\mathrm{pH} \leq 4.0$ (Fig. 3).

$\mathrm{Fe}^{3+}+\mathrm{H}_{2} \mathrm{O}+h v \quad \rightarrow \quad \mathrm{Fe}^{2+}+\mathrm{H}^{+}+\mathrm{HO}^{\bullet}$

$\mathrm{Fe}^{2+}+\mathrm{H}_{2} \mathrm{O}_{2} \quad \rightarrow \quad \mathrm{Fe}^{3+}+\mathrm{OH}^{-}+\mathrm{HO}^{\circ}$

For comparison, classical heterogeneous photo-Fenton experiments are conducted at $\mathrm{pH}=4.0 \mathrm{using}$ different synthetic iron oxides/hydroxides, namely goethite and hematite (Fig. S7) while a previous work using magnetite is already reported (Huang $\mathrm{W}$ et al. 2017). It is clear that ferrate-mediated photo-Fenton oxidation is more advantageous due to (i) the first degradation stage of BPA by ferrate (until $t=60 \mathrm{~min}$ ) and (ii) the more efficient heterogeneous photo-Fenton process. This second stage is almost two times more efficient than in classical heterogeneous processes and it is due to the presence of oxides with different physico-chemical properties (Batarseh et al. 2007; Miklos et al. 2018; Wang et al. 2016).

\subsubsection{Valorization of ferrate using natural and non-toxic compounds}

In order to design a sustainable process for wastewater treatment, the decrease of $\mathrm{pH}$ in the ferratebased treatment could be operated using compounds of natural origin. Ascorbic acid (AA) is an excellent candidate since it is an antioxidant substance contained in many fruits and vegetables. In addition, AA has reducing and complexing properties that are able to improve the iron cycle (Hou et al. 2016, 2018; Huang X et al. 2017). Different amounts of AA are added to ferrate/BPA system after $60 \mathrm{~min}$, then the solution was left for next 30 min before addition of $\mathrm{H}_{2} \mathrm{O}_{2}(1 \mathrm{mM})$ (Fig. 4). The initial $60 \mathrm{~min}$ reaction and induction time of $30 \mathrm{~min}$ were necessary to avoid degradation of AA by ferrate and to allow efficient reduction of $\mathrm{Fe}(\mathrm{III})$ into $\mathrm{Fe}(\mathrm{II})$. The $\mathrm{Fe}$ (II) released in solution is stabilized by the formation of $\mathrm{Fe}(\mathrm{II})$-ascorbate complex, thus improving the iron cycle (Hou et al. 2016, 2018; Huang X et al. 2017). The use of AA obviously improves the ferrate-mediated oxidation process (Fig. 4). Control experiments are performed with only AA and $\mathrm{H}_{2} \mathrm{O}_{2}$ (Fig. S8) and no degradation of BPA was observed. The efficient removal of BPA was assigned to enhanced photolysis of Fe(III) and Fenton reactions (R2 and R3). The difference between dark (Fig. 4A) and irradiated systems (Fig. 4B) was 
the net contribution of UVA light which accelerates the BPA removal extents from +10 to $+20 \%$ according to the AA concentration. This enhancement obtained under UVA is explained by considering the photolysis of $\mathrm{Fe}(\mathrm{III})$ into $\mathrm{Fe}(\mathrm{II})$ which is reported in Fig. 5. After addition of $1 \mathrm{mM}$ of AA after $60 \mathrm{~min}$, the concentration of $\mathrm{Fe}(\mathrm{II})$ increases up to $12.5 \mu \mathrm{M}$ at $\mathrm{t}>90 \mathrm{~min}$. Then, the concentration drops after the addition of $1 \mathrm{mM}^{\circ} \mathrm{H}_{2} \mathrm{O}_{2}$ due to its consumption by the Fenton reaction (R3). Under UVA, the decrease of Fe(II) concentration is less pronounced due to its renewal from Fe(III) photolysis (R2). An interesting point is that under UVA and beyond $180 \mathrm{~min}$, the degradation reaction still continues (Fig. 4A) which is consistent to the constant increase of Fe(II) under UVA (Fig. 5). On the other hand, in the dark, the degradation efficiency reaches its limit after 180 min (Fig. 4B) with no more change in $\mathrm{Fe}(\mathrm{II})$ concentration suggesting that $\mathrm{H}_{2} \mathrm{O}_{2}$ is the limiting reactant (R3).

By comparison, similar experiments are performed using lower concentration of ferrate $\left(0.01 \mathrm{~g} \mathrm{~L}^{-1}\right.$; Fig. S9). Briefly, even if the concentration of produced $\mathrm{Fe}(\mathrm{II})$ is approximatively 2 times less than in the system containing $0.04 \mathrm{~g} \mathrm{~L}^{-1}$ of ferrate, the maximum BPA degradation extent was approximatively unchanged (around 95\%). At $0.04 \mathrm{~g} \mathrm{~L}^{-1}$ of ferrate, when AA concentration increased to $1.0 \mathrm{mM}$, the initial $\mathrm{pH}$ of 10.0 decreased to 4.6 which is more beneficial for Fenton-based processes (Fig. 4). However, at higher concentration (1.5 mM), it is possible to see a negative effect on the BPA degradation (Fig. 4) which is due to a significant quenching effect on generated hydroxyl radicals by the antioxidant.

Although the use of AA is a promising way to valorize the ferrate decomposition byproducts, it is necessary to investigate another strategy since acidic $\mathrm{pH}$ cannot be considered for viable wastewater treatment. Therefore, one key parameter is the use of iron complexing agent to increase the $\mathrm{pH}$ of the ferrate-mediated heterogeneous photo-Fenton process at environmentally relevant conditions. EDDS is an efficient iron complexing agent and a harmless substitute to EDTA. Different amounts of EDDS were added to the ferrate/BPA system after 60 min followed by addition of $\mathrm{H}_{2} \mathrm{O}_{2}(1 \mathrm{mM}) 30 \mathrm{~min}$ later (Fig. 6). Prior to the addition of EDDS, the pH was fixed at 6.0 \pm 0.2 while the UVA irradiation was turned on once EDDS was just added to the solution in order to improve the dissolution of $\mathrm{Fe}(\mathrm{III})$ (R4 and R5). Indeed, EDDS leads to the formation of a soluble and reactive form of iron at near neutral pH. Moreover, Fe(III)-EDDS complex could modify the redox potential of iron since this soluble complex can contribute to both oxidative and reductive steps of Fenton-like chemistry (Huang et al. 2013).

$$
\begin{array}{lll}
>\mathrm{Fe}(\mathrm{III})+\mathrm{EDDS} & \rightarrow & \mathrm{Fe}(\mathrm{III})-\mathrm{EDDS} \\
\mathrm{Fe}(\mathrm{III})-\mathrm{EDDS}+h v & \rightarrow & \mathrm{Fe}(\mathrm{II})+\mathrm{EDDS}^{\bullet}
\end{array}
$$


The total iron concentration increased from 20 to $40 \mu \mathrm{M}$ in presence of $50 \mu \mathrm{M}$ of EDDS under UVA (Fig. 6A). The concentration of $\mathrm{Fe}(\mathrm{II})$ follows a similar trend. After addition of $\mathrm{H}_{2} \mathrm{O}_{2}$, the concentration of iron decreases (Fig. 6A) due to the consumption of soluble Fe(II) and Fe(III) species by the (photo)Fenton-based processes. Concerning the BPA degradation, the combination of EDDS and UVA irradiation at $\mathrm{t}=60$ min followed by addition of $\mathrm{H}_{2} \mathrm{O}_{2}$ at $\mathrm{t}=90 \mathrm{~min}$ in the ferrate/BPA system (Fig. 6B) improved the BPA degradation extent after 180 min compared to the ferrate alone (+20\%). The optimal EDDS concentration was found to be $50 \mu \mathrm{M}$ since either low amount $(20 \mu \mathrm{M})$ or excess of EDDS $(200 \mu \mathrm{M})$ limited the BPA degradation. This is explained by the lower quantity of iron transferred in solution at lower EDDS concentration while the involvement of this organic ligand at higher concentration is detrimental due to the reactivity with hydroxyl radicals. The pH which was monitored during the BPA degradation in the photochemical ferrate/EDDS/ $\mathrm{H}_{2} \mathrm{O}_{2}$ system slightly increased from 6.0 to 6.7. Although the valorization of oxidation by ferrate using EDDS appeared less efficient than in the case of ascorbic acid, the strong advantage of the ferrate-mediated heterogeneous photo-Fenton process is the possible use at circumneutral $\mathrm{pH}$ and thus, its potential application to real wastewater treatment.

\subsubsection{Application to municipal wastewater treatment}

In order to investigate the feasibility of the above ferrate-mediated heterogeneous photo-Fenton oxidation process, treatment of municipal wastewater spiked by BPA is performed using the optimal conditions described above (the photochemical system using $0.04 \mathrm{~g} \mathrm{~L}^{-1}$ of ferrate with $1 \mathrm{mM} \mathrm{H}_{2} \mathrm{O}_{2}$ in the presence of either $1 \mathrm{mM}$ AA or $50 \mu \mathrm{M}$ EDDS) (Fig. 7). The $\mathrm{pH}$ after the first oxidation step by ferrate is adjusted at 6.7. It was worth noting that the efficiency of oxidation by ferrate was not affected by the WW matrix since BPA degradation extents reached also $45 \%$ after $300 \mathrm{~min}$. This indicates that ferrate has a better reactivity towards BPA than humic substances which account for most of the organic matter in WW. Due to the presence of other components in WW playing the role of scavengers (Table S1), the observed degradation extents of BPA are logically lower than in the synthetic water. By increasing the concentration of AA and EDDS, slight increase in the BPA degradation is obtained (Fig. 7). It is interesting to observe that, in WW, the ferrate-mediated heterogeneous photo-Fenton treatment in presence of AA is more affected than using EDDS, compared to the degradation extents of BPA obtained in synthetic water. Indeed, in synthetic water, almost $100 \%$ of BPA was removed by the AA-enhanced treatment (Fig. 4A) while in WW, a maximum of 63\% degradation extent is observed (Fig. 7A). On the other hand, for the EDDS-enhanced treatment, 68\% (Fig. 6B) and 60\% (Fig. 7B) of BPA is degraded in synthetic 
water and WW, respectively. These results can be explained by the non-selective reactivity of AA which does not react exclusively with iron species in the treated wastewater, while EDDS is rather selective in the formation of $\mathrm{Fe}(\mathrm{III})$ complexes. In addition, the organic matter present in wastewater probably has a complexation/stabilization effect on aqueous iron (Garcia Ballesteros et al. 2017). Therefore, the EDDSenhanced ferrate-mediated heterogeneous photo-Fenton treatment is considered as the most viable for municipal WW treatment in our experimental conditions.

\section{Conclusions}

In this work, we investigated for the first time the combination of two oxidation processes in an innovative one called ferrate-mediated heterogeneous photo-Fenton process. In our experimental conditions, oxidation by ferrate only removed $45 \%$ of bisphenol A (BPA). Since ferrate was decomposed in solid iron oxides species, including crystallized magnetite, their valorization in different heterogeneous photo-Fenton processes were performed for the first time. Under UVA, which is a part of solar radiation, and in presence of either ascorbic acid or EDDS which are natural origin and non-toxic compounds, we designed an environmentally friendly and sustainable wastewater treatment. Indeed, UVA is known to trigger Fe(III) photolysis while AA and EDDS are able to reduce $\mathrm{Fe}(\mathrm{III})$ into $\mathrm{Fe}(\mathrm{II})$ and to efficiently complex $\mathrm{Fe}(\mathrm{III})$, respectively. In our experimental conditions, almost complete degradation of BPA in synthetic water was observed using AA-enhanced ferrate-mediated photochemical system while $68 \%$ BPA removal was obtained using EDDS in this new treatment method. However, this latter ferrate-mediated heterogeneous photo-Fenton process was the most viable for real WW treatment since it can be used at circumneutral $\mathrm{pH}$ and the effect of WW matrix has a smaller impact. Therefore, the application of the EDDS-enhanced treatment was the most promising for municipal WW spiked by BPA with a degradation extent of $60 \%$. This work highlighted a new possibility to consider wastewater treatments via a modified process based on oxidation by ferrate which is a promising and innovative strategy in the enhancement of persistent organic pollutants degradation in water.

\section{Acknowledgements}

Authors acknowledge financial support from the CAP 20-25 I-site project and the Fédération des Recherches en Environnement (FRE) through the CPER "Environment" founded by the region AURA, the French government and the European Commission (FEDER). OM also acknowledges the financial support for the post-doctoral provided by University Clermont Auvergne. 


\section{References}

Batarseh ES, Reinhart DR, Daly L (2007) Liquid sodium ferrate and Fenton's reagent for treatment of mature landfill leachate. J. Environ. Eng. 133:1042-1050.

Chen J, Wu N, Xu X, Qu R, Li C, Pan X, Wei Z, Wang Z (2018) Fe(VI)-mediated single-electron coupling processes for the removal of chlorophene: A combined experimental and computational study. Environ. Sci. Technol. 52:12592-12601.

Crain DA, Eriksen M, Iguchi T, Jobling S, Laufer H, LeBlanc GA, Guillette LJ (2007) An ecological assessment of bisphenol-A: Evidence from comparative biology. Reprod. Texicol. 24:225-239.

Dong F, Liu J, Li C, Lin Q, Zhang T, Zhang K, Sharma VK (2019) Ferrate(VI) pre-treatment and subsequent chlorination of blue-green algae: Quantification of disinfection byproducts. Environ. Int. 133: 105195.

Feng M, Cizmas L, Wang Z, Sharma VK (2017) Synergistic effect of aqueous removal of fluoroquinolones by a combined use of peroxymonosulfate and ferrate(VI). Chemosphere 177:144-148.

Feng M, Jinadatha C, McDonald TJ, Sharma VK (2018) Accelerated pxidation of organic contaminants by Ferrate(VI): The overlooked role of reducing additives. Environ. Sci. Technol. 52:11319-11327.

Feng M, Sharma VK (2018) Enhanced oxidation of antibiotics by ferrate(VI)-sulfur(IV) system: Elucidating multi-oxidant mechanism. Chem. Eng. J. 341:137-145.

Feng M, Baum JC (2019) Oxidation of sulfonamide antibiotics of six-membered heterocyclic moiety by Ferrate(VI): Kinetics and mechanistic insight into $\mathrm{SO}_{2}$ extrusion. Environ. Sci. Technol. 53:2695-2704.

Garcia Ballesteros S, Constante M, Vicente R, Mora M, Amat AM, Arques A, Carlos L, Garcia Einschlag FS (2017) Humic-like substances from urban waste as auxiliaries for photo-Fenton treatment: a fluorescence EEMPARAFAC study. Photochem. Photobiol. Sci. 16:38-45.

Goodwill JE, Jiang Y, Reckhow DA, Gikonyo J, Tobiason JE (2015) Characterization of particles from Ferrate preoxidation. Environ. Sci. Technol. 49:4955-4962.

Han Q, Wang H, Dong W, Liu T, Yin Y, Fan H (2015) Degradation of bisphenol A by ferrate(VI) oxidation: Kinetics, products and toxicity assessment. Chem. Eng. J. 262:34-40.

Han Q, Dong W, Wang H, Liu T, Tian Y, Song X (2018) Degradation of tetrabromobisphenol A by ferrate(VI) oxidation: Performance, inorganic and organic products, pathway and toxicity control. Chemosphere 198:92102.

Hou X, Huang X, Ai Z, Zhao J, Zhang L (2016) Ascorbic acid/Fe@ $\mathrm{Fe}_{2} \mathrm{O}_{3}$ : A highly efficient combined Fenton reagent to remove organic contaminants. J. Hazard. Mater. 310:170-178.

Hou X, Huang X, Li M, Zhang Y, Yuan S, Ai Z, Zhao J, Zhang L (2018) Fenton oxidation of organic contaminants with aquifer sediment activated by ascorbic acid. Chem. Eng. J. 348:255-262.

Huang W, Brigante M, Wu F, Mousty C, Hanna K, Mailhot G (2013) Assessment of the Fe(III)-EDDS complex in Fenton-like processes: From the radical formation to the degradation of bisphenol A. Environ. Sci. Technol. 47:1952-1959. 
Huang W, Luo M, Wei C, Wang Y, Hanna K, Mailhot G (2017) Enhanced heterogeneous photo-Fenton process modified by magnetite and EDDS: BPA degradation. Environ. Sci. Pollut. Res. Int. 24:10421-10429.

Huang W, Bianco A, Brigante M, Mailhot G (2018) UVA-UVB activation of hydrogen peroxide and persulfate for advanced oxidation processes: Efficiency, mechanism and effect of various water constituents. J. Hazard. Mater. 347:279-287.

Huang X, Hou X, Jia F, Song F, Zhao J, Zhang L (2017) Ascorbate-promoted surface iron cycle for efficient heterogeneous Fenton alachlor degradation with hematite nanocrystals. ACS Appl. Mater. Interfaces 9:8751-8758.

Jiang JQ, Lloyd B (2002) Progress in the development and use of ferrate(VI) salt as an oxidant and coagulant for water and wastewater treatment. Water Res. 36:1397-1408.

Jiang JQ (2007) Research progress in the use of ferrate(VI) for the environmental remediation. J. Hazard. Mater. 146:617-623.

Jiang Y, Goodwill JE, Tobiason JE, Reckhow DA (2015) Effect of different solutes, natural organic matter, and particulate Fe(III) on Ferrate(VI) decomposition in aqueous solutions. Environ. Sci. Technol. 49:2841-2848.

Jiang JQ, Stanford C, Petri M (2018) Practical application of ferrate(VI) for water and wastewater treatment Site study’s approach. Water-Energy Nexus 1:42-46.

Lee Y, Kissner R, von Gunten U (2014) Reaction of Ferrate(VI) with ABTS and Self-Decay of Ferrate(VI): Kinetics and Mechanisms. Environ. Sci. Technol. 48:5154-5162.

Licht S, Naschitz V, Halperin L, Halperin N, Lin L, Chen J, Ghosh S, Liu B (2001) Analysis of ferrate(VI) compounds and super-iron Fe(VI) battery cathodes: FTIR, ICP, titrimetric, XRD, UV/VIS, and electrochemical characterization. J. Power Sources 101:167-176.

Luo C, Feng M, Sharma VK, Huang CH (2019) Oxidation of pharmaceuticals by ferrate(VI) in hydrolyzed urin: Effects of major inorganic constituents. Environ. Sci. Technol. 53:5272-5281.

Lv D, Zheng L, Zhang H, Deng Y (2018) Coagulation of colloidal particles with ferrate(VI). Environ. Sci. Water Res. Technol. 4:701-710.

Ma Y, Zhang K, Li C, Zhang T, Gao N (2015) Oxidation of sulfonamides in aqueous solution by UV-TiO $2^{-}$ Fe(VI). Bio-Med. Res. Int. http://dx.doi.org/10.1155/2015/973942.

Machalova Siskova K, Jancula D, Drahos B, Machala L, Babica P, Alonso PG, Travnicek Z, Tucek J, Marsalek B, Sharma VK, Zboril R (2016) High-valent iron (FeVI, FeV, and FeIV) species in water: characterization and oxidative transformation of estrogenic hormones. PCCP 18:18802-18810.

Matin AR, Yousefzadeh S, Ahmadi E, Mahvi A, Alimohammadi M, Aslani H, Nabizadeh R (2018) A comparative study of the disinfection efficacy of $\mathrm{H}_{2} \mathrm{O}_{2}$ /ferrate and $\mathrm{UV} / \mathrm{H}_{2} \mathrm{O}_{2}$ /ferrate processes on inactivation of Bacillus subtilis spores by response surface methodology for modeling and optimization. Food Chem. Toxicol. 116:129-137.

Miklos DB, Remy C, Jekel M, Linden KG, Drewes JE, Hübner U (2018) Evaluation of advanced oxidation processes for water and wastewater treatment - A critical review. Water Res. 139:118-131. 
Monfort O, Usman M, Soutrel I, Hanna K (2019) Ferrate(VI) based chemical oxidation for the remediation of aged PCB contaminated soil: Comparison with conventional oxidants and study of limiting factors. Chem. Eng. J. 355:109-117.

Nomiri S, Hoshyar R, Ambrosino C, Tyler CR, Mansouri B (2019) A mini review of bisphenol A (BPA) effects on cancer related cellular signaling pathways. Environ. Sci. Pollut. Res. 26:8459-8467.

Peings V, Pigot T, Baylere P, Sotiropoulos JM, Frayret J (2017) Removal of pharmaceuticals by a potassium ferrate(VI) material: from practical implementation to reactivity prediction. Environ. Sci. Water Res. Technol. 3:699-709.

Prucek R, Hermanek M, Zboril R (2009) An effect of iron(III) oxides crystallinity on their catalytic efficiency and applicability in phenol degradation - A competition between homogeneous and heterogeneous catalysis. Appl. Catal. A Gen. 366:325-332.

Rush JD, Bielski BHJ (1994) Decay of Ferrate(V) in Neutral and Acidic Solutions. A Premix Pulse Radiolysis Study. Inorg. Chem. 33:5499-5502.

Rush JD, Zhao Z, Bielski BHJ (1996) Reaction of Ferrate (VI)/Ferrate (V) with Hydrogen Peroxide and Superoxide Anion - a Stopped-Flow and Premix Pulse Radiolysis Study. Free Radical Res. 24:187-198.

Shao B, Dong H, Sun B, Guan X (2019) Role of Ferrate(IV) and Ferrate(V) in activating Ferrate(VI) by calcium sulfite for enhanced oxidation of organic contaminants. Environ. Sci. Technol. 53:894-902.

Sharma VK, Burnett CR, Rivera W, Joshi VN (2001) Heterogeneous photocatalytic reduction of Ferrate(VI) in UV-irradiated titania suspensions. Langmuir 17:4598-4601.

Sharma VK (2002) Potassium ferrate(VI): an environmentally friendly oxidant. Adv. Environ. Res. 6:143-156.

Sharma VK (2010) Oxidation of inorganic compounds by Ferrate(VI) and Ferrate(V): One-electron and twoelectron transfer steps. Environ. Sci. Technol. 44:5148-5152.

Sharma VK, Graham NJ, Li XZ, Yuan BL (2010) Ferrate(VI) enhanced photocatalytic oxidation of pollutants in aqueous TiO2 suspensions. Environ. Sci. Pollut. Res. Int. 17:453-461.

Sharma VK, Luther GW, Millero FJ (2011) Mechanisms of oxidation of organosulfur compounds by ferrate(VI). Chemosphere 82:1083-1089.

Sharma VK (2013) Ferrate(VI) and ferrate(V) oxidation of organic compounds: Kinetics and mechanism. Coord. Chem. Rev. 257:495-510.

Sharma VK, Zboril R, Varma RS (2015) Ferrates: greener oxidants with multimodal action in water treatment technologies. Acc. Chem. Res. 48:182-191.

Sharma VK, Chen L, Zboril R (2016) Review on high valent FeVI (Ferrate): A sustainable green oxidant in organic chemistry and transformation of pharmaceuticals. ACS Sustain. Chem. Eng. 4:18-34.

Stookey LL (1970) Ferrozine-a new spectrophotometric reagent for iron. Anal. Chem. 42:779-781.

Sun S, Pang S, Jiang J, Ma J, Huang Z, Zhang J, Liu Y, Xu C, Liu Q, Yuan Y (2018) The combination of ferrate(VI) and sulfite as a novel advanced oxidation process for enhanced degradation of organic contaminants. Chem. Eng. J. 333:11-19. 
Suzuki T, Nakagawa Y, Takano I, Yaguchi K, Yasuda K (2004) Environmental fate of bisphenol A and its biological metabolites in river water and their xeno-estrogenic activity. Environ. Sci. Technol. 38:2389-2396.

Velo-Gala I, López-Penalver JJ, Sanchez-Polo M, Rivera-Utrilla J (2014) Comparative study of oxidative degradation of sodium diatrizoate in aqueous solution by $\mathrm{H}_{2} \mathrm{O}_{2} / \mathrm{Fe}^{2+}, \mathrm{H}_{2} \mathrm{O}_{2} / \mathrm{Fe}^{3+}$, Fe (VI) and $\mathrm{UV}, \mathrm{H}_{2} \mathrm{O}_{2} / \mathrm{UV}$, $\mathrm{K}_{2} \mathrm{~S}_{2} \mathrm{O}_{8} /$ UV. Chem. Eng. J. 241:504-512.

Wang ZP, Huang LZ, Feng XN, Xie P, Liu ZZ (2010) Removal of phosphorus in municipal landfill leachate by photochemical oxidation combined with ferrate pre-treatment. Desalin. Water Treat. 22:111-116.

Wang N, Zheng T, Zhang G, Wang P (2016) A review on Fenton-like processes for organic wastewater treatment. J. Environ. Chem. Eng. 4:762-787.

Wang X, Dong W, Brigante M, Mailhot G (2019) Hydroxyl and sulfate radicals activated by Fe(III)-EDDS/UV: Comparison of their degradation efficiencies and influence of critical parameters. Appl. Cat. B. Env. 245:271278.

Xie X, Chang H (2019) A simple treatment method for phenylarsenic compounds: Oxidation by ferrate(VI) and simultaneous removal of the arsenate released with in situ formed Fe(II) oxide-hydroxide. Environ. Int. 127:730741.

Yu H, Chen J, Xie H, Ge P, Kong Q, Luo Y (2017) Ferrate(vi) initiated oxidative degradation mechanisms clarified by DFT calculations: a case for sulfamethoxazole. Environ. Sci. Process Impacts 19:370-378.

Zboril R, Andrle M, Oplustil F, Machala L, Tucek J, Filip J, Marusak Z, Sharma VK (2012) Treatment of chemical warfare agents by zero-valent iron nanoparticles and ferrate(VI)/(III) composite. J. Hazard. Mater. 211212:126-130.

Zhang J, Zhu L, Shi Z, Gao Y (2017) Rapid removal of organic pollutants by activation sulfite with ferrate. Chemosphere 186:576-579.

Zheng L, Deng Y (2016) Settleability and characteristics of ferrate(VI)-induced particles in advanced wastewater treatment. Water Res. 93:172-178. 